\title{
HIGH PERFORMANCE LIQUID CHROMATOGRAPHY METHOD FOR QUANTIFICATION OF THE N-PHENYLPIPERAZINE DERIVATIVE LASSBIO-579 IN RAT PLASMA
}

Daniela J. Conrado, Stela Maris Kuze Rates and Teresa Dalla Costa*

Faculdade de Farmácia, Universidade Federal do Rio Grande do Sul, Av. Ipiranga, 2752, 90610-000, Porto Alegre - RS, Brazil Carlos Alberto Manssour Fraga and Eliezer J. Barreiro

Faculdade de Farmácia, Universidade Federal do Rio de Janeiro, CP 68006, 21944-970, Rio de Janeiro - RJ, Brazil

Recebido em 8/12/06; aceito em 23/4/07; publicado na web em 5/10/07

\begin{abstract}
A rapid HPLC analytical method was developed and validated for the determination of the N-phenylpiperazine derivative LASSBio579 in plasma rat. Analyses were performed using a C18 column and elution with $20 \mathrm{mM}$ sodium dihydrogen phosphate monohydrate - methanol. The analyte was monitored using a photodiode array detector $(257 \mathrm{~nm})$. Calibration curves in spiked plasma were linear over the concentration range of $0.3-8 \mu \mathrm{g} / \mathrm{mL}$ with determination coefficient $>0.99$. The lower limit of quantification was 0.3 $\mu \mathrm{g} / \mathrm{mL}$. The applicability of the HPLC method for pharmacokinetic studies was tested using plasma samples obtained after administration of LASSBio-579 to Wistar rats, showing the specificity of the method.
\end{abstract}

Keywords: LASSBio-579; HPLC; pharmacokinetics.

\section{INTRODUCTION}

The search for more efficient dopaminergic drugs is a very active research field. The conventional antipsychotic drugs are important to treat the positive symptoms of schizophrenia, but they are less efficient to treat the negative symptoms. Moreover, conventional antipsychotics produce extrapyramidal side effects due to blockage of $\mathrm{D}_{2}$ receptors in the nigrostriatal pathway ${ }^{1,2}$. Clozapine, atypical antipsychotic prototype, displays significant affinity for a large number of other receptors such as $\mathrm{D}_{4}$ dopamine and 5-hydroxytryptamine receptors. It presents an improved therapeutic profile, i.e., improved efficacy on both positive and negative symptoms and decreased side effects. However, clozapine induces agranulocytosis in approximately $1-2 \%$ of patients ${ }^{3,4}$.

Aiming to obtain more efficient dopaminergic drugs devoid of hematological side effects, LASSBio-581 (1-[1-(4-chloro-phenyl)$1 \mathrm{H}-[1,2,3]$ triazol-4-ylmethyl]-4-phenyl-piperazine) and LASSBio579 (1-[1-(4-chloro-phenyl)-1H-pyrazol-4-ylmethyl]-4-phenylpiperazine) were designed and synthetized by molecular hybridization of clozapine and L-741, a selective ligand for $\mathrm{D}_{2}$ dopamine receptors ${ }^{5}$ (Figure 1).

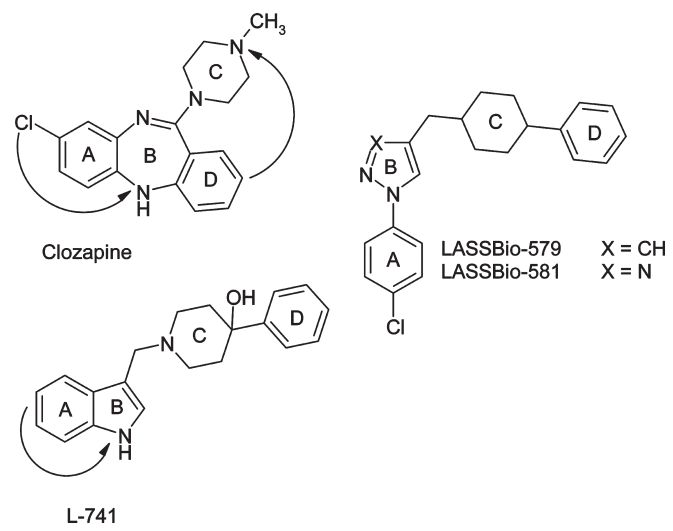

Figure 1. Structural design concept of LASSBio-579 and LASSBio-581

*e-mail: teresadc@farmacia.ufrgs.br
Brain homogenates of the LASSBio-581 and LASSBio-579 were submitted to binding studies showing selectivity to $\mathrm{D}_{2}$ receptors. Moreover, electrophysiological studies carried out in cultured hippocampal neurons suggested that both compounds act as $D_{2}$ agonists ${ }^{5}$. The compounds were also assayed (dose range of 15-40 $\mathrm{mg} / \mathrm{kg}$ ) in three experimental models: blockage of amphetamine (30 mg/kg, ip)-induced stereotypy in rats; the catalepsy test in mice, and apomorphine (1 mg/kg, ip)-induced hypothermia in mice. On the basis of the results of catalepsy and amphetamine-induced stereotypy, the compounds demonstrated an inhibitory effect on dopaminergic behavior ${ }^{6}$.

Therefore, considering the promising pharmacodynamic results obtained on dopaminergic system, it is important to determine the pharmacokinetic profiles of LASSBio-581 and LASSBio-579, which can become prototype drugs to treat schizophrenia. In order to perform the pre-clinical pharmacokinetic evaluation, it is necessary to have a sensitive analytical method for the quantification of the drug in biological matrix. Tasso and co-workers (2003) validated a high performance liquid chromatography (HPLC) method for the determination of LASSBio-581 in rat plasma ${ }^{7}$. The method was successfully used to determine LASSBio-581 plasma pharmacokinetic profile and tissue distribution in a pre-clinical study ${ }^{8}$.

In this work, a HPLC method was developed and validated for the determination of LASSBio-579 in rat plasma using ketoconazole (Figure 2) as internal standard (IS). The bioanalytical method was validated considering the specificity, linearity, precision, accuracy and lower limit of quantification. The HPLC method was applied to the analysis of plasma samples obtained after intravenous administration of LASSBio-579 to male Wistar rats.

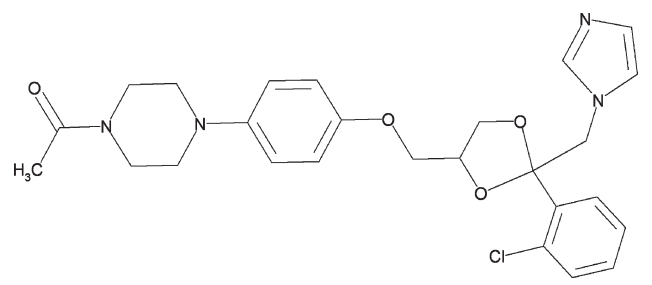

Figure 2. Chemical structure of the internal standard ketoconazole 


\section{EXPERIMENTAL}

\section{Solvents and chemicals}

LASSBio-579 (hydrochloride) was synthesized by the Laboratório de Avaliação e Síntese de Substâncias Bioativas (LASSBio, Rio de Janeiro, Brazil) as described by Menegatti and co-workers5 . Analytical grade sodium dihydrogen phosphate monohydrate and sodium hydroxide were obtained from Merck (Darmstat, Germany). HPLC grade methanol and acetonitrile were purchased from Merck (Darmstat, Germany). HPLC water was obtained from a Millipore's Milli-Q System and used throughout the analysis.

\section{Preparation of standard solutions and quality control samples}

Two separate weighing of LASSBio-579 were used to prepare standard stock solutions at $500 \mu \mathrm{g} / \mathrm{mL}$ in methanol. One stock solution was used to prepare standard working solutions for the calibration curve standards. The other stock solution was used to prepare standard working solutions for the quality control (QC) samples. The calibration curve samples were prepared by spiking $100 \mu \mathrm{L}$ of Wistar rat plasma with $10 \mu \mathrm{L}$ of the appropriate standard working solution to obtain LASSBio-579 final concentrations of $0.3,0.4,0.5,0.75$, 2.0, 4.0 and $8.0 \mu \mathrm{g} / \mathrm{mL}$. Quality control samples were prepared at $0.35,1.5$ and $6.0 \mu \mathrm{g} / \mathrm{mL}$. New standard stock solutions, calibration curve and QC samples were prepared on each analysis day.

Standard stock solution of ketoconazole (IS) was prepared at 500 $\mu \mathrm{g} / \mathrm{mL}$ in acetonitrile. This solution was successively diluted with acetonitrile to result in a final concentration of $6 \mu \mathrm{g} / \mathrm{mL}$ of ketoconazole.

\section{Instrumentations}

Chromatographic analysis was carried out on a Shimadzu liquid chromatograph, using LC-10ADVP solvent delivery system with low-pressure gradient flow control valve FCV-10ALVP, SCL-10AVP system controller, SPD-M10AVP photodiode array detector and DGU-14A degasser. The injections were performed by a Shimadzu SIL-10ADVP automatic injector and the analyses were performed using Shimadzu CLASS-VP software (Version 6.12).

\section{Sample preparation}

Prior to the chromatographic analysis, $100 \mu \mathrm{L}$ of plasma samples were deproteinized by addition of $200 \mu \mathrm{L}$ of acetonitrile (containing $6 \mu \mathrm{g} / \mathrm{mL}$ of IS), vortexed for $30 \mathrm{~s}$ and centrifuged at $6800 \mathrm{~g}, 21^{\circ} \mathrm{C}$ for $15 \mathrm{~min}$. The supernatant was separated to inject into the HPLC system. Ketoconazole final concentrations in the samples was 4 $\mu \mathrm{g} / \mathrm{mL}$. All plasma samples, including calibration curve, QC and samples from pharmacokinetic experiments were processed in the same manner.

\section{Chromatographic conditions}

The mobile phase used for the chromatographic separation was composed of $20 \mathrm{mM}$ sodium dihydrogen phosphate monohydrate methanol (20:80, v/v, apparent $\mathrm{pH} 8.8)$. The mobile phase was filtered before using and it was delivered isocratically at a flow rate of 1.0 $\mathrm{mL} / \mathrm{min}$. The analysis was carried out at room temperature using Shimadzu Shim-pack HPLC column (150 mm x $4.6 \mathrm{~mm}$ i.d.) packed with $5 \mu \mathrm{m}$ ODS stationary phase, protected by Waters Novapak guard column packed with $4 \mu \mathrm{m}$ RP18 material. The autosampler was set to inject $150 \mu \mathrm{L}$ sample aliquots and the analyte was monitored using a photodiode array detector at $257 \mathrm{~nm}$.

\section{Validation procedures}

Standard calibration curve and QC samples were analyzed in three consecutive days. Linearity of calibration curves based on peak-area ratio (area of analyte/area of IS) as function of the nominal concentration was assessed by least square regression. Slopes, intercepts and determination coefficients were calculated. The selectivity of the method was investigated for potential interferences of endogenous substances by using eight independent batches of rat plasma samples. Moreover, the chromatograms of the experimental samples obtained after intravenous administration of LASSBio-579 to Wistar rats were compared to the calibration curve standards chromatograms in order to detect interfering peaks. Intra- and inter-day precision and accuracy of the analytical method were shown by triplicate processing and following analysis of QC samples $(0.35,1.5$ and $6.0 \mu \mathrm{g} / \mathrm{mL}$ ). Precision was calculated as relative standard deviation (RSD) of the experimental concentrations and accuracy as the comparison between the experimental and nominal samples concentration. The criteria for acceptability of the data included accuracy within $\pm 15 \%$ deviation from the nominal values and precision within $\pm 15 \% \mathrm{RSD}$, except for the lower limit of quantification (LLOQ), where it should not exceed $20 \%$ of $\mathrm{RSD}^{9}$. Recovery experiments (extraction efficiency) were performed by comparing the analytical results for CQ extracted samples $(n=3)$ with unextracted standard solutions that represent $100 \%$ recovery.

\section{Preliminary stability studies}

Preliminary studies were carried out to evaluate LASSBio-579 stability under the conditions used in this work. Analyte stability was determined during blood sample collection and handling at room temperature for $2 \mathrm{~h}$ and after freezing for 15 days at $-20{ }^{\circ} \mathrm{C}$. Furthermore, the stability of the processed samples was determined at $4{ }^{\circ} \mathrm{C}$ for $24 \mathrm{~h}$ in the autosampler.

\section{Pharmacokinetic study}

The protocol of this animal study was approved by the Ethics in Research Committee of the Universidade Federal do Rio Grande do Sul (\#2003239, UFRGS, Porto Alegre, Brazil). The applicability of the HPLC method developed for pharmacokinetic studies was tested using plasma samples obtained after intravenous administration of LASSBio-579 to male Wistar rats $(n=3)$. The animals were kept under controlled $12 \mathrm{~h}$ light-dark cycle during the acclimation period and had access to water and food ad libitum. LASSBio-579 for intravenous administration was prepared in $5 \%$ glucose solution by heating at $60{ }^{\circ} \mathrm{C}$, resulting in a concentration of $2 \mathrm{mg} / \mathrm{mL}$. About 1.5 $\mathrm{mL}$ of the LASSBio-579 solution was administered to rats corresponding at $10 \mathrm{mg} / \mathrm{kg}$ dose. Blood samples were withdrawn from lateral tail vein at $0.08 ; 0.25 ; 0.50 ; 1 ; 1.5 ; 2 ; 4 ; 6 ; 9 \mathrm{~h}$ after administration. Blood samples were collected into heparinized reaction tubes and centrifuged at $6800 \mathrm{~g}$ at $21^{\circ} \mathrm{C}$ for $15 \mathrm{~min}$ to obtain plasma, which was stored at $-20{ }^{\circ} \mathrm{C}$ until analysis. Plasma $(100 \mu \mathrm{L})$ samples were processed as described in Sample preparation.

\section{RESULTS AND DISCUSSION}

\section{Selectivity and recovery}

The selectivity of the analytical methodology can be observed in Figure. 3 by comparing representative chromatograms of independent blank plasma (a), blank plasma spiked with LASSBio-579 (0.3 $\mu \mathrm{g} / \mathrm{mL})$ and IS (4.0 $\mu \mathrm{g} / \mathrm{mL})$ (b) and blank plasma spiked with 
LASSBio-579 $(8.0 \mu \mathrm{g} / \mathrm{mL})$ and IS $(4.0 \mu \mathrm{g} / \mathrm{mL})(\mathrm{c})$. No additional peaks due to endogenous substances were observed that would interfere with the detection of the interesting compounds. In addition, the experimental chromatograms obtained after intravenous administration of LASSBio-579 (10 mg/kg) to Wistar rats (Figure. 3d) did not show interfering metabolites. The retention times of LASSBio-579 and IS were approximately 6.5 and $5.5 \mathrm{~min}$, respectively. The extraction recovery of LASSBio-579 was approximately $98.7 \%$ regardless of the analyte concentration on the sample.

\section{Linearity}

The linearity of the method was observed in the investigated concentration range $(0.3$ to $8 \mu \mathrm{g} / \mathrm{mL})$. LASSBio- 579 calibration curve parameters determined in three consecutive validation days are shown in Table 1. Calibration curves of peak area ratio (LASSBio-579/IS) as function of nominal concentration were linear, presenting a determination coefficient greater than or equal to 0.998 for all curves.

\section{Lower limit of quantification}

The lower limit of quantification (LLOQ) was $0.3 \mu \mathrm{g} / \mathrm{mL}$, which was accepted as the lowest level on the calibration curve that could be determined with appropriate precision and accuracy under the experimental conditions of this analytical method (Tables 2 and 3) ${ }^{9}$.

\section{Precision and accuracy}

The intra- e inter-day relative standard deviation values for LASSBio-579 are shown in Table 2. The intra-assay and inter-assay precision (RSD) values for QC samples were less than or equal to
Table 1. Calibration curve parameters and statistics for LASSBio579 in rat plasma

\begin{tabular}{lccc}
\hline Curve & Slope & y-Intercept & $\begin{array}{c}\text { Determination } \\
\text { coefficient }\end{array}$ \\
\hline Day 1 & & & \\
1 & 0.2571 & -0.0044 & 0.9999 \\
2 & 0.2543 & 0.0061 & 0.9999 \\
3 & 0.2785 & -0.0202 & 0.9982 \\
Day 2 & & & \\
1 & 0.2798 & 0.0160 & 0.9985 \\
2 & 0.2610 & -0.0085 & 0.9995 \\
3 & 0.2588 & -0.0065 & 0.9996 \\
Day 3 & & & \\
1 & 0.2555 & -0.0055 & 0.9989 \\
2 & 0.2607 & -0.0103 & 0.9982 \\
3 & 0.2390 & 0.0040 & 0.9999 \\
Mean (n = 9) & 0.2605 & & \\
S.D. ${ }^{a}$ & 0.0124 & & \\
R.S.D. $(\%)^{\mathrm{b}}$ & 4.77 & & \\
\hline
\end{tabular}

${ }^{\text {a }}$ S.D., standard deviation; ${ }^{\text {b }}$ R.S.D., relative standard deviation

5.44 and $4.64 \%$, respectively. The method showed an accuracy within $15 \%$, which can be observed in Table 3 . The results obtained for LASSBio-579 HPLC quantification method were within the acceptable limits stated for bioanalytical methods validation?.

\section{Stability}

Preliminary studies showed that LASSBio-579 was stable under the conditions used in this work. The analyte was stable in blood samples at room temperature for $2 \mathrm{~h}(99.6 \%)$ and in plasma samples after freezing at $-20^{\circ} \mathrm{C}$ for 15 days $(98.5 \%)$. The stability of processed
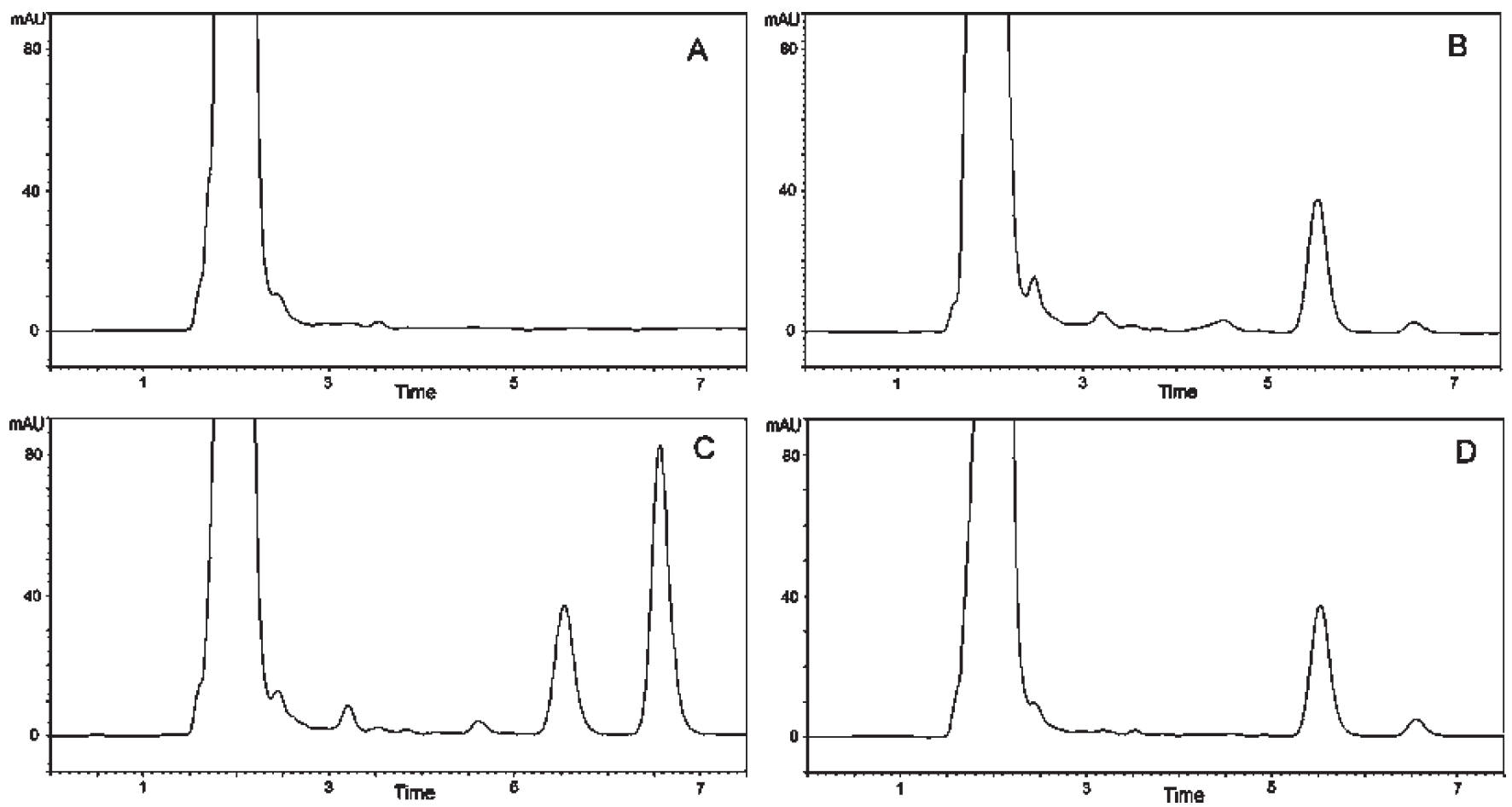

Figure 3. Representative HPLC chromatograms in rat plasma: (A) blank plasma, (B) plasma spiked with LASSBio-579 and IS (0.3 and $4.0 \mu \mathrm{gg} / \mathrm{mL}$, respectively), (C) plasma spiked with LASSBio-579 and IS (8.0 and $4.0 \mu \mathrm{g} / \mathrm{mL}$, respectively), (D) plasma sample 9 h post-administration of $10 \mathrm{mg} / \mathrm{kg}$ i.v. LASSBio-579 (plasma concentration $0.5 \mu \mathrm{g} / \mathrm{mL})$ with IS $(4.0 \mu \mathrm{g} / \mathrm{mL})$. The retention times observed were: I.S. $-5.5 \mathrm{~min}$ and LASSBio-579 - $6.5 \mathrm{~min}$ 
Table 2. Intra and inter-day variation of LASSBio-579 in rat plasma

\begin{tabular}{lcccc}
\hline Nominal concentration & Day & \multicolumn{3}{c}{ Experimental concentrations } \\
& & & \\
& Mean $(\mu \mathrm{g} / \mathrm{mL})$ & S.D. & R.S.D.\% \\
\hline Intra-day variation & & & & \\
$0.3 \mu \mathrm{g} / \mathrm{mL}$ (LLOQ) & 1 & 0.29 & 0.03 & 10.59 \\
& 2 & 0.33 & 0.03 & 7.65 \\
& 3 & 0.32 & 0.04 & 11.47 \\
& & & & \\
$0.35 \mu \mathrm{g} / \mathrm{mL}$ & 1 & 0.35 & 0.008 & 2.20 \\
& 2 & 0.35 & 0.018 & 5.13 \\
& 3 & 0.37 & 0.005 & 1.37 \\
$1.5 \mu \mathrm{g} / \mathrm{mL}$ & & & & \\
& 1 & 1.41 & 0.077 & 5.44 \\
& 2 & 1.44 & 0.048 & 3.34 \\
& 3 & 1.54 & 0.070 & 4.58 \\
$6.0 \mu \mathrm{g} / \mathrm{mL}$ & & & & \\
& 1 & 5.84 & 0.307 & 5.26 \\
& 2 & 5.58 & 0.268 & 4.80 \\
& 3 & 5.82 & 0.120 & 2.06 \\
Inter-day variation & & & & \\
$0.3 \mu \mathrm{g} / \mathrm{mL}$ (LLOQ) & & & & \\
$0.35 \mu \mathrm{g} / \mathrm{mL}$ & & 0.31 & 0.02 & 5.84 \\
$1.5 \mu \mathrm{g} / \mathrm{mL}$ & & 1.46 & 0.013 & 3.68 \\
$6.0 \mu \mathrm{g} / \mathrm{mL}$ & & 5.74 & 0.143 & 2.49 \\
\hline
\end{tabular}

a Values (mean and S.D.) represent $\mathrm{n}=3$ observations.

Table 3. Accuracy for the analysis of LASSBio-579 in rat plasma

\begin{tabular}{lcc}
\hline Concentration $(\mu \mathrm{g} / \mathrm{mL})$ & Range $(\mu \mathrm{g} / \mathrm{mL})$ & Accuracy $(\%)^{\mathrm{a}}$ \\
\hline 0.3 (LLOQ) & $0.27-0.34$ & $90.0-113.3$ \\
0.35 & $0.33-0.38$ & $94.3-108.6$ \\
1.5 & $1.34-1.61$ & $89.3-107.3$ \\
6.0 & $5.28-6.11$ & $88.0-101.8$ \\
\hline
\end{tabular}

${ }^{\mathrm{a}} \mathrm{n}=9$ observations.

samples was determined at $4{ }^{\circ} \mathrm{C}$ in the autosampler. LASSBio-579 and internal standard did not degrade at this condition, showing $101.2 \%$ and $99.3 \%$ recoveries, respectively, after $24 \mathrm{~h}$.

\section{Applicability of the analytical method}

To investigate the suitability of the analytical method developed and validated it was applied to determine LASSBio-579 plasma profile after intravenous administration of $10 \mathrm{mg} / \mathrm{kg}$ in a pilot pharmacokinetic study $(n=3)$. The mean plasma profile obtained is shown in Figure 4. The results indicated that the analytical method is suitable to measure plasma concentrations of the compound in pre-clinical studies. The estimated half-life was found to be $2.6 \pm 0.3 \mathrm{~h}$. LASSBio-579 total clearance and volume of distribution at steady state were $0.23 \pm 0.05$ $\mathrm{L} / \mathrm{h} / \mathrm{kg}$ and $0.34 \pm 0.06 \mathrm{~L} / \mathrm{kg}$, respectively. The area under the plasma concentration versus time curve from time zero to infinity $\left(\mathrm{AUC}_{0-\infty}\right)$ was $44.1 \pm 9.0 \mu \mathrm{g} \mathrm{h} / \mathrm{mL}$. The results show that the LLOQ of the method developed for LASSBio-579 was low enough to allow its use in pharmacokinetic studies because the extrapolated AUC was around $4.5 \pm 1.8 \%$, showing that the elimination phase of the compound was adequately characterized.

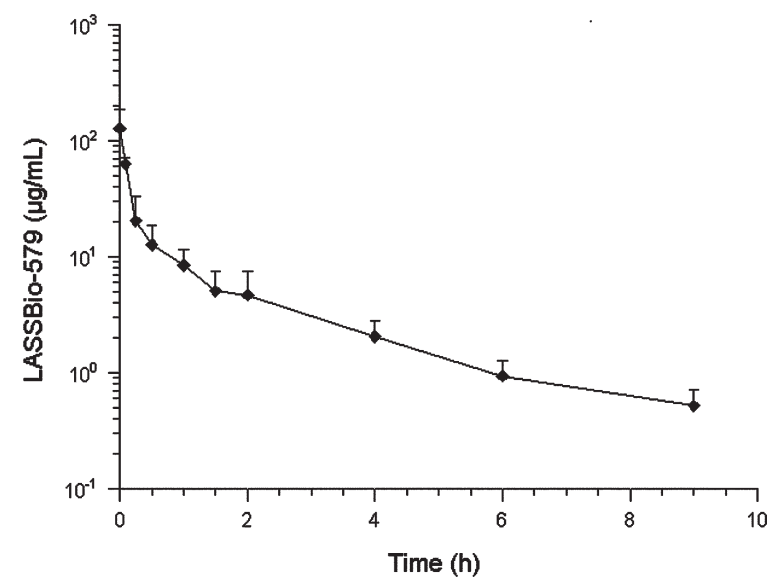

Figure 4. Mean plasma concentration-time of LASSBio-579 after single intravenous dose of $10 \mathrm{mg} / \mathrm{kg}$ to male Wistar rats (mean $+S . D$. $)(n=3)$

\section{CONCLUSIONS}

In conclusion, a simple, accurate and sensitive HPLC method has been developed for analysis of LASSBio-579 in rat plasma, using ketoconazole as IS. This method was succesfully applied to determine the concentration-time profiles of LASSBio-579 in preclinical pharmacokinetic pilot study.

\section{ACKNOWLEDGEMENTS}

The authors acknowledge PROCAD/CAPES-Brazil (Process 002/01-5) and IM-INOFAR/CNPq-Brazil (Process 420.015/05-1) for the financial support. D. J. Conrado thanks CAPES-Brazil for individual grant.

\section{REFERENCES}

1. Graeff, F. G.; Guimarães, F. S.; Zuardi, A. W. In Fundamentos de Psicofarmacologia; Graeff, F. G.; Guimarães, F. S., eds.; Ateneu: São Paulo, 1999.

2. Baldessarini, R. J.; Tarazi, F. I. In Goodman \& Gilman's The Pharmacological Basis of Therapeutics; Hardman, J. G.; Limbird, L. E., eds.; McGraw-Hill: New York, 2001.

3. Svensson, T. H.; Clin. Neurosci. Res. 2003, 3, 34.

4. Gaszner, P.; Makkos, Z.; Prog. Neuro-Psychopharmacol. Biol. Psychiatr. 2004, 28, 465 .

5. Menegatti, R.; Cunha, A. C.; Ferreira, V. F.; Perreira, E. F. R.; El-Nebawi, A.; Eldefrawi, A. T.; Albuquerque, E. X.; Neves, G.; Rates, S. M. K.; Fraga, C. A. M.; Barreiro, E. J.; Bioorg. Med. Chem. 2003, 11, 4807.

6. Neves, G.; Fenner, R.; Heckler, A. P.; Viana, A. F.; Tasso, L.; Menegatti, R.; Fraga, C. A. M.; Barreiro, E. J.; Dalla Costa, T.; Rates, S. M. K.; Braz. J. Med. Biol. Res. 2003, 36, 625.

7. Tasso, L.; Neves, G.; Menegatti, R.; Fraga, C. A. M.; Barreiro, E. J.; EiflerLima, V. L.; Rates, S. M. K.; Dalla Costa, T.; J. Pharm. Biomed. Anal. 2003, 33, 1127.

8. Tasso, L.; Neves, G.; Menegatti, R.; Fraga, C. A. M.; Barreiro, E. J.; EiflerLima, V. L.; Rates, S. M. K.; Dalla Costa, T.; Eur. J. Pharm. Sci. 2005, 26 , 194.

9. http://www.fda.gov/cder/guidance/index.htm, accessed in November 2006. 